\section{1 CiênCIA CIDADÃ \\ Envolver não cientistas em pesquisas pode apoiar a aprendizagem e o engajamento do público com a ciência}

Ciência não é assunto só para cientistas. E quando pessoas que não estão diretamente envolvidas nas diferentes áreas científicas decidem participar, todo mundo ganha. É o que mostra o relatório da National Academies of Sciences, Engineering and Medicine, dos Estados Unidos, publicado no final de outubro de 2018. O documento aponta que estudos científicos envolvendo não cientistas apoiam o aprendizado, contribuindo para uma participação mais ativa do público na ciência, e também podem servir como uma ferramenta valiosa para facilitar pesquisas em larga escala. $\mathrm{O}$ relatório "Learning through citizen science - enhancing opportunities by design" foi escrito por um comitê de 12 membros presidido por Rajul Pandya, diretor da American Geophysical Union (AGU).

A participação ativa de não cientistas na ciência cada vez mais vem demonstrando que pode beneficiar tanto a população quanto os próprios cientistas. "A ciência cidadã le- vanta questôes sobre quem participa da ciência, o que significa essa participação, quem decide quais questôes científicas investigar e até que tipo de conhecimento e prática contam”, escreve Pandya no prefácio do relatório. Assim, ela abrange tanto projetos em que cientistas incluem o público (por exemplo, recrutando voluntários para um recenseamento de aves ou para monitorar a qualidade do ar e da água) quanto os que a própria população busca conhecimento técnico para resolver um problema (avaliando como o aumento das temperaturas ou o desmatamento podem afetar sua comunidade).

A ciência cidadã não significa, entretanto, "alfabetizar" o público, mas sim incentivá-lo a participar ativamente das diversas áreas da ciência - e aprender com essa troca. "Devemos falar de construção de diálogos, em que cientistas e sociedade se ouçam. Isto quer dizer que tanto o cientista precisa aceitar que a sociedade também possui conhecimentos, saberes e percepções adquiridas e que são válidos, quanto o público precisa entender que o fazer científico envolve um conjunto de procedimentos que servem para delimitar e garantir a verificabilidade das afirmações que são produzidas", aponta a historiadora Márcia Regina Barros da Silva, professora do Departamento de História, da Faculdade de Filosofia, Ciências e Letras da USP e vice-presidente da Associação Brasileira de Estudos Sociais das Ciências e da Tecnologia (Esocite.br.).

INCLUSÃO Uma das grandes vantagens da participação cidadã é trazer a diversidade para a prática científica, já que oferece uma oportunidade única de receber conhecimentos, práticas e habilidades diversos de todas as pessoas envolvidas. No entanto, essa oportunidade só pode ser concretizada se a diversidade, a equidade e a inclusão estiverem presentes em sua concepção e implementação. Segundo o relatório, não considerar aspectos como a diversidade de educação, experiências, oportunidades e recursos nos projetos de ciência cidadã pode levar à perpetuação da desigualdade. Por outro lado, quando se respeita a diversidade dos atores envolvidos, a ciência cidadã promove uma rica interação social entre cientistas e não cientistas, proporcionando uma valiosa troca de conhecimentos e experiências. "Com a participação mais ativa e engajada da sociedade em projetos científicos tende a haver um envolvimento maior em temas de ciência de interesse público, o que não só motiva futuras gerações para a prática científica como também colabora com a disseminação da cultura científica de uma maneira geral", aponta o físico Marcelo Knobel, reitor da Unicamp. 


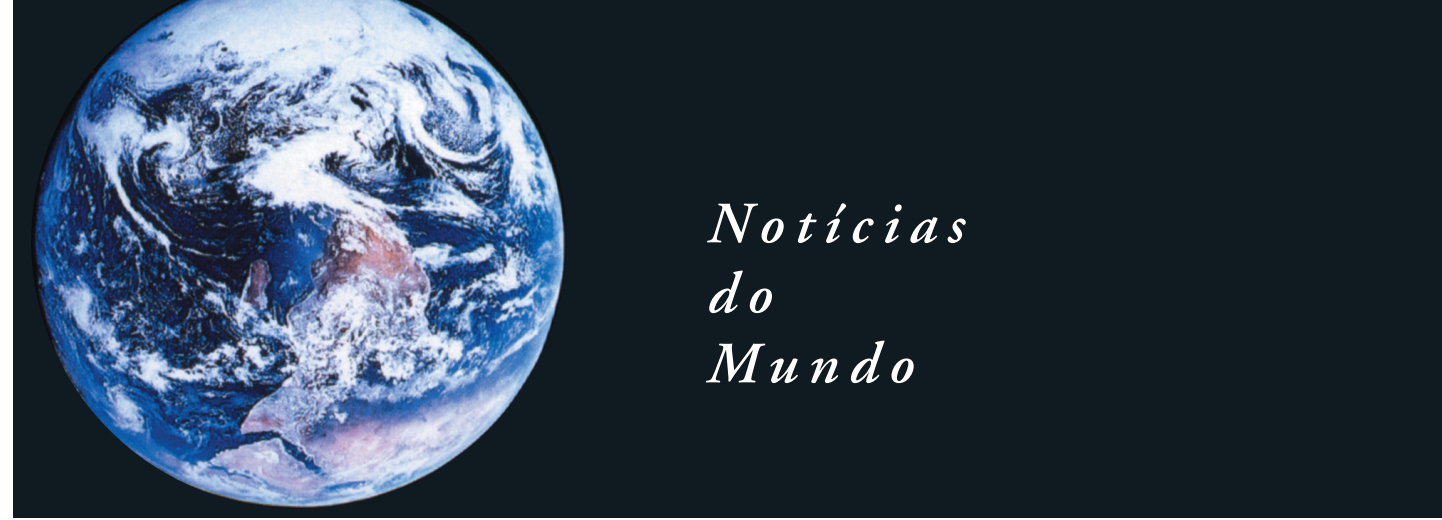

Além disso, os projetos de ciência cidadã estimulam o aprendizado mas, para tanto, devem considerar o público ao qual se destina, o engajamento de todas as partes interessadas, $o$ incentivo da interação social e o suporte à aprendizagem. "Os projetos de ciência cidadã podem ajudar os participantes a aprender práticas científicas e conteúdo, mas apenas se forem desenhados para apoiar o aprendizado", declarou Pandya. O relatório recomenda que todas as partes interessadas (cientistas e não cientistas) estejam envolvidos na elaboração do projeto, garantindo tanto a inclusão quando a aprendizagem.

FAZENDO CIÊNCIA A ciência cidadã não apenas está crescendo como também está se tornando mais complexa e conectada. Existem projetos desde a construção de contadores Geiger para avaliar os níveis de radiação, até fazer fotos de água parada para ajudar a documentar a disseminação de doenças transmitidas por mosquitos. Nos Estados Unidos, por exemplo, vêm se destacando projetos como o The Air Quality Egg (AQE), uma plataforma na internet em que os cidadãos monitoram poluentes do ar; o Asteroid Zoo, um projeto em que voluntários procuram e classificam asteroides desconhecidos, sinalizando aqueles potencialmente perigosos, ou seja, muito próximos à Terra; e o NOAA Cooperative
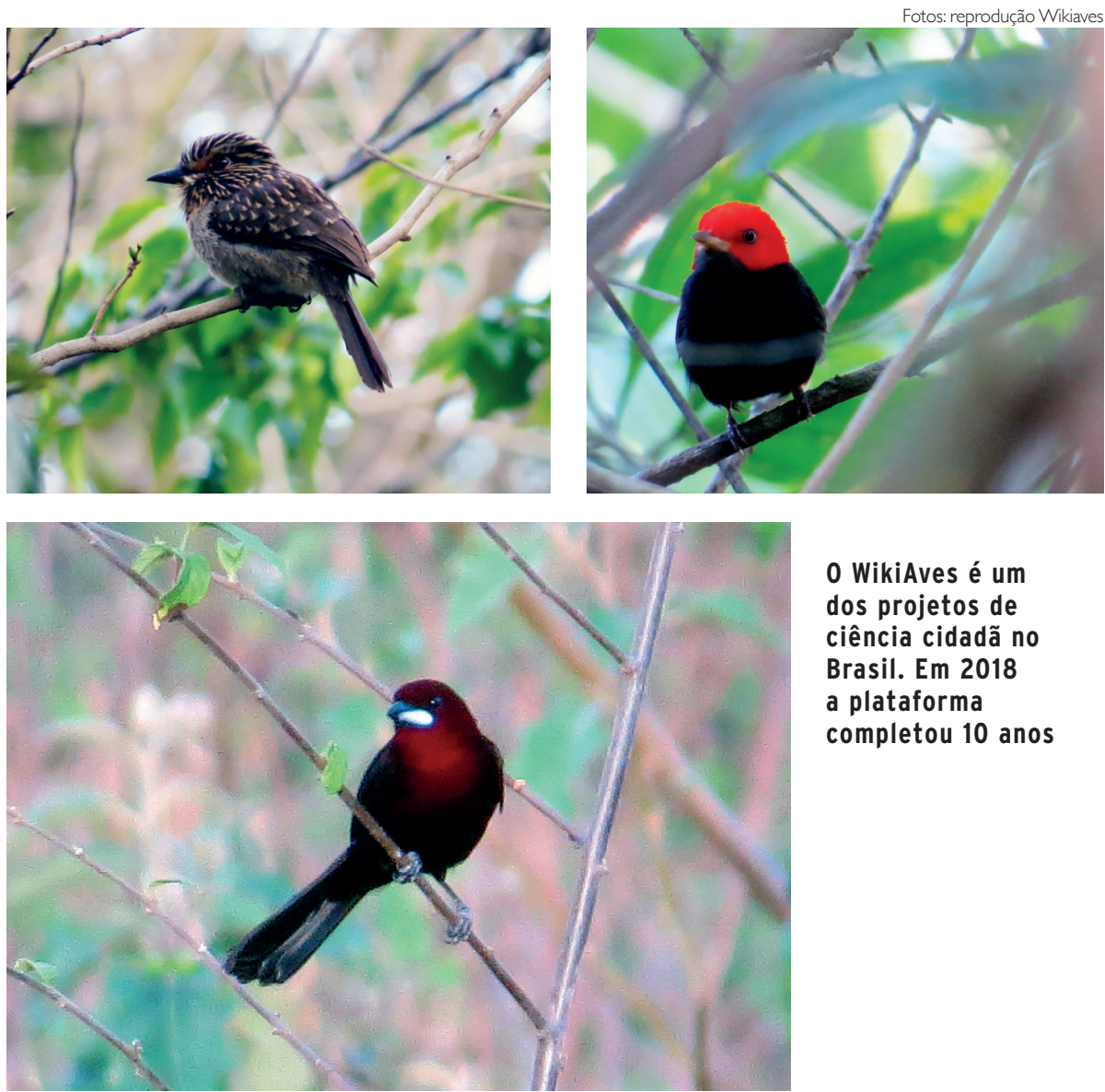

0 WikiAves é um dos projetos de ciência cidadã no Brasil. Em 2018 a plataforma completou 10 anos

Observer Program (COOP), uma rede de observadores meteorológicos com mais de 8.700 voluntários que monitoram as condiçōes climáticas - e até o nível das marés - nos 50 estados americanos.

O Brasil também possui vários projetos em andamento. "Há projetos interessantes na internet que aproveitam a capacidade ociosa de milhares de computadores para decifrar códigos genéticos, por exemplo.
Ou ainda para acompanhamento de índices de poluição (sonora, do ar), condições do clima e umidade em grandes cidades. Creio que há ainda um espaço imenso para que esses projetos cresçam e se desenvolvam cada vez mais", aponta Knobel.

Um dos projetos mais antigos é o Atlas de Registros de Aves Brasileira (ARA), que faz o registro de ocorrências e também reúne informações sobre a biologia das espécies e ações 


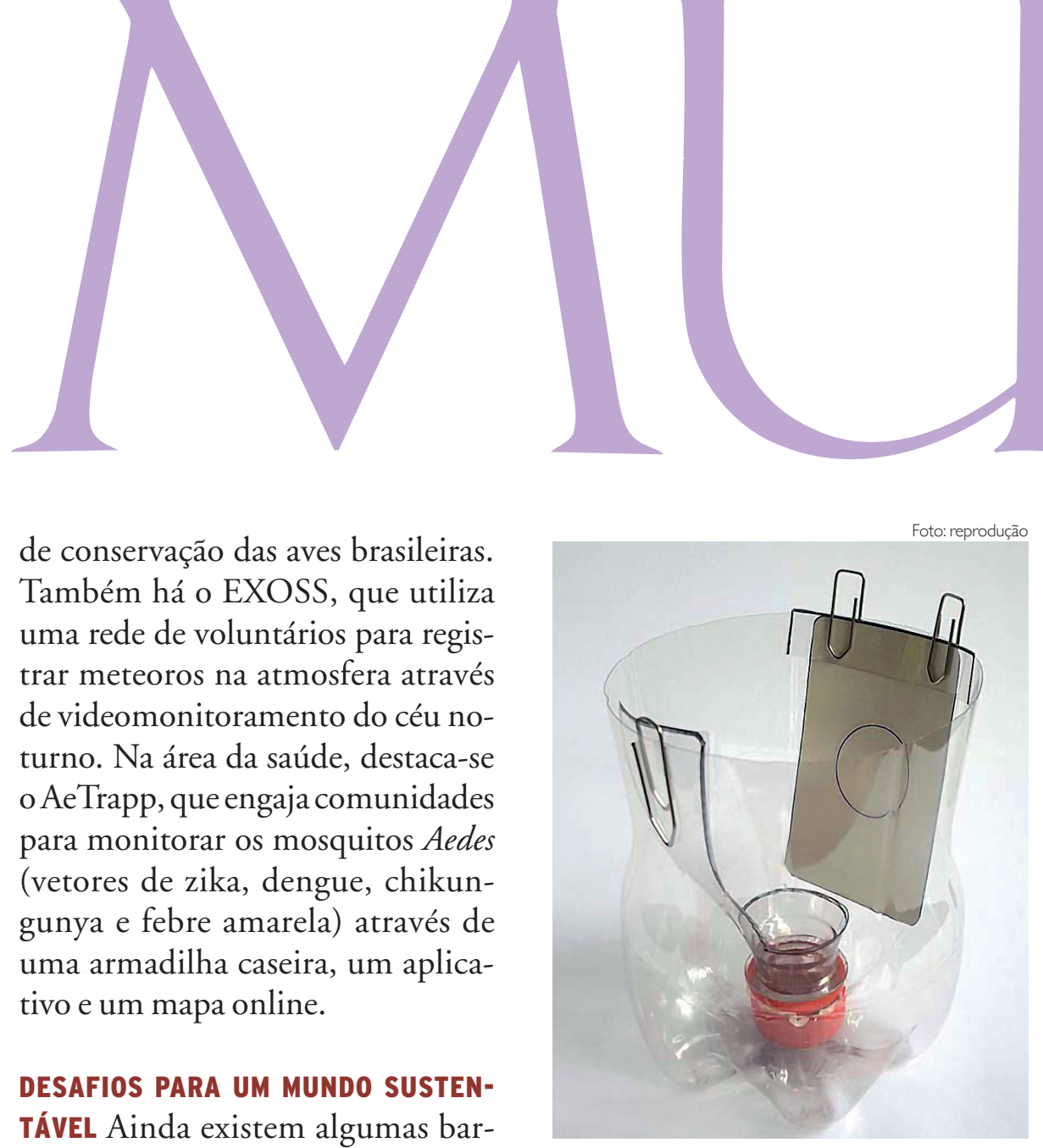

reiras a serem vencidas pela ciência cidadã, como a confiabilidade dos dados medidos. Mas ainda assim, cada vez mais os cientistas envolvidos acreditam que ela possa trazer respostas importantes para questões prementes $\mathrm{da}$ atualidade. $\mathrm{E}$ apostam nessa parceria. "A sociedade deve participar da ciência e também na própria formulação de políticas públicas que não podem ser deixadas apenas nas mãos de especialistas, sob o perigo de perda de contato com a história", alerta Silva. "O desconhecimento sobre os projetos das ciências traz perda de autonomia para o público frente às transformações globais nas quais as ciências e as tecnologias têm papel importante. Para o cientista também não é bom o distanciamento. Ele perde apoio, perde a credibilidade do grande público e passa a
Armadilha caseira para dengue ajuda a monitorar mosquito da dengue

falar apenas com seus círculos de especialistas".

As expectativas são grandes. Espera-se que a ciência cidadã se torne uma fonte importante de dados e análises de alta qualidade em áreas relevantes para os formuladores de políticas públicas, assim como para os próprios cientistas. Em 2017, foi criado o grupo mundial Citizen Science Global Partnership para promover a ciência cidadã para um mundo sustentável, visando enfrentar os desafios globais que vão desde a fome até a degradação ambiental. "Embora a ciência cidadã tenha crescido em popularidade nas últimas décadas, ela não é uma ideia nova. Há exemplos do que chamamos de 'ciência cidadā' que remontamà China antiga, há3.500 anos", aponta Sean Ryan, pesquisador da Universidade do Estado da Carolina do Norte (EUA) e autor de estudo sobre ciência cidadã recentemente publicado na revista Proceedings of the Royal Society B. "Em todas as áreas que examinamos, descobrimos que a ciência cidadã tem sido usada tanto para produzir descobertas cientificamente robustas que abordam questôes do mundo real, quanto para engajar o público".

PESQUISA EM LARGa ESCALA Uma das principais vantagens é realizar pesquisa em grande escala. O Zooniverse, uma plataforma online com mais de 1,7 milhão de usuários cadastrados e mais de 50 projetos de ciência cidadã ativos, talvez seja um dos maiores exemplos. Para se ter uma ideia de sua dimensão (e do tamanho que um projeto de ciência cidadã pode alcançar), o Galaxy Zoo - o primeiro e um dos mais famosos projetos do Zooniverse, que visa a classificação de galáxias - conta com mais de 17 mil voluntários, que colaboraram com 1.388.446 classificações. Mais de 50 artigos foram publicados a partir desses dados coletados. Outro projeto que mostra o grande alcance da ciência cidadã foi realizado recentemente na Bélgica. Foram distribuídos medidores 


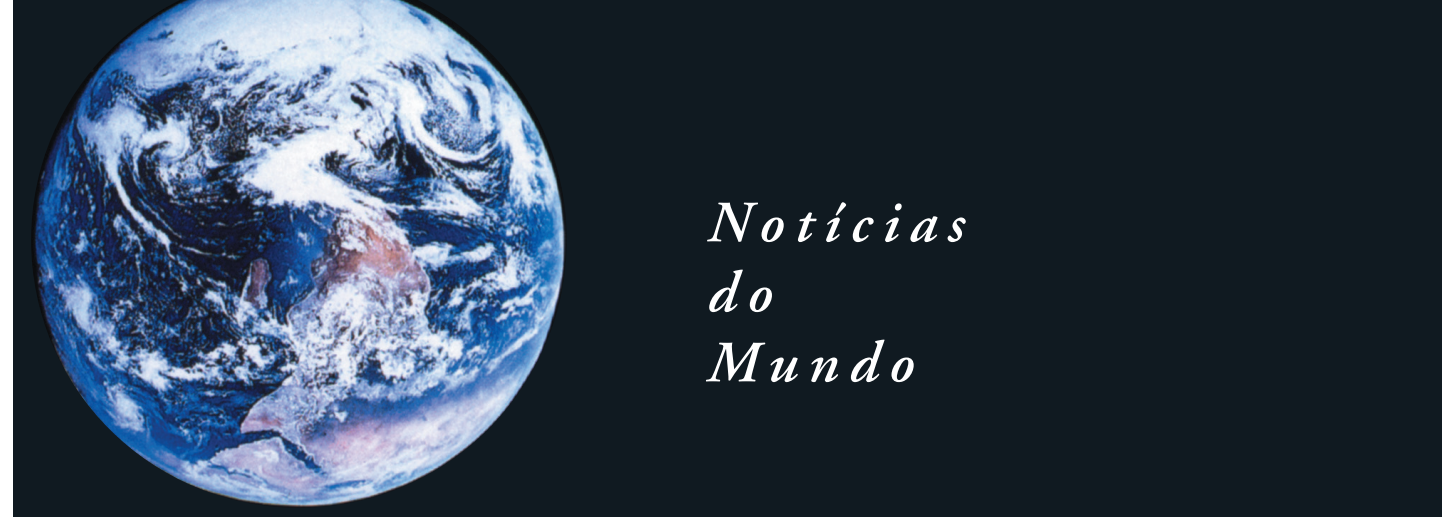

de poluição atmosférica a 20 mil participantes que fizeram leituras durante um mês. Eles colheram dados sobre as concentraçôes de dióxido de nitrogênio "na altura do nariz" - um nível não medido pelos satélites - em mais de $17 \mathrm{mil}$ pontos diferentes.

NoBrasil, um exemploéoWikiAves, um banco de dados online sobre as aves brasileiras que recebe colaborações de voluntários. Todos os registros passam antes pela análise de um especialista. Em apenas um ano, o projeto recebeu mais de 900 fotos e 62 gravações de sons de pássaros. Hoje a plataforma possui $100 \mathrm{mil}$ registros de sons, um milhão de fotos e um milhão de registros de aves silvestres brasileiras.

A ciência cidadã possibilita projetos de grande escala que não teriam recursos para existir de outra forma. Um estudo publicado na revista BioScience em 2016 mostrou que para cada hora treinando cientistas cidadãos os cientistas recebem em retorno nove horas de coleta de dados - ou seja, a ajuda do público é crucial para coletar tantos dados sobre questôes que afetam o meio ambiente, o clima, a atmosfera e até a saúde. O trabalho de voluntários no projeto Zooniverse ajudou a economizar mais de US\$1,5 milhão para os pesquisadores.

Chris Bueno

\section{ACESSO A PERIÓdICOS}

\section{Plano $S$ expõe conflitos no mercado de edição de artigos científicos}

Na maioria das vezes, pesquisadores brasileiros têm acesso a artigos produzidos no país sem ter que pagar para grandes oligopólios editoriais como Elsevier, Blackwell e Springer. No entanto, no resto do mundo, a situação se inverte. Segundo Abel Packer, diretor do portal SciELO (Scientific Electronic Library Online), uma biblioteca eletrônica que abrange uma coleção selecionada de periódicos científicos brasileiros, no Brasil $80 \%$ dos periódicos têm acesso aberto e gratuito - devido ao pioneirismo da plataforma que comemora 20 anos em 2018 - enquanto, no restante dos países, somente $25 \%$ dos artigos científicos não dependem de editoras comerciais. Entretanto, o panorama mundial fundado no modelo clássico de assinaturas de revistas científicas está sendo alvo de iniciativas da União Europeia pelo livre acesso - e causa polêmica. Aprovado em setembro de 2018 por um grupo de onze fundações públicas europeias de financiamento à pesquisa, o Plano $S$ determina que, até janeiro de 2020 , todas as pesquisas financiadas com dinheiro público sejam publicadas em revistas de acesso aberto. Hoje, treze países são signatários do Plano $S$ que estabelece princípios como a manutenção de direitos autorais e garantias para que taxas recaiam sobre instituições e não sobre pesquisadores/ leitores individualmente. Duas importantes fundações de apoio à pesquisa biomédica, a Wellcome Trust, de Londres, e a Bill and Melinda Gates Foundation, de Washington, também anunciaram que vão seguir esse modelo nas pesquisas por elas financiadas.

CUSTO DUPLICADO No modelo atual, governos e as fundações pagam duas vezes: quando financiam pesquisas e quando tem que acessar os artigos onde os resultados foram publicados. "É um duplo oligopólio", afirmou Claire Lemercier no programa de rádio France Culture (11/10/18). Ela foi presidente do conselho científico do portal OpenEdition e atualmente é membro do conselho científico do CNRS (Centre National de la Recherche Scientifique). 